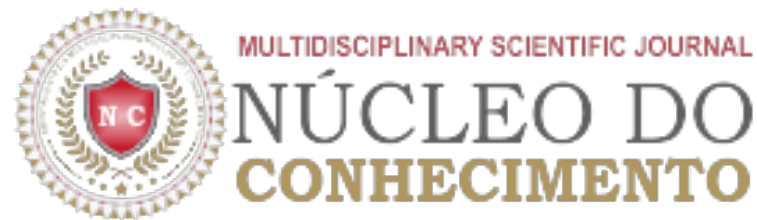

\section{Prevalência de Sintomas Depressivos em Acadêmicos de Enfermagem de uma Faculdade Privada em Belém-PÁ}

TRINDADE, Fábyla d' Tácia Brito [1] , GOMES, Nathalia Neves [2] , FERREIRA, Sandra Elizia Gonçalves ${ }^{[3]}$,MOREIRA, Elisângela Claudia de Medeiros ${ }^{[4]}$,OLIVEIRA, Margaret de ${ }^{[5]}$ DENDASCK, Carla Viana ${ }^{[6]}$,OLIVEIRA, Euzébio de ${ }^{[7]}$

TRINDADE, Fábyla d' Tácia Brito. Et.al. Prevalência de Sintomas Depressivos em Acadêmicos de Enfermagem de uma Faculdade Privada em Belém-PÁ. Revista Científica Multidisciplinar Núcleo do Conhecimento. Ed. 11, Ano 02, Vol. 04, pp. 24-38, Novembro de 2017. ISSN:2448-0959, Link de acesso: https://www.nucleodoconhecimento.com.br/saude/sintomas-depressivos-academicos-enfermagem, DOI: 10.32749/nucleodoconhecimento.com.br/saude/sintomas-depressivos-academicos-enfermagem

\section{RESUMO}

A proposta deste artigo foi identificar a prevalência de sintomas depressivos em acadêmicos de enfermagem do $1^{\circ}, 4^{\circ}$ e $8^{\circ}$ períodos de uma faculdade privada em Belém-Pa. Pesquisa de abordagem quantitativa de caráter exploratório e o instrumento utilizado foi o Inventário de Depressão de Back-11. Numa amostra de 147 acadêmicos, 69 (46,94\%) não apresentaram sintomas depressivos, 42 (28,57\%) apresentaram sintomas leve, $31(21,08 \%)$ apresentaram sintomas moderado e $5(3,40 \%)$ apresentaram sintomas severo. A maioria dos acadêmicos apresentou indicativos de sintomas de depressão entre leve e moderada. Foi observada uma alteração maior nos resultados do $8^{\circ}$ período, o que, de certa forma está de acordo com outras pesquisas realizadas com estudantes da área da saúde, para esta fase do curso. É importante destacar, também, um alto índice de sintomas de depressão severa no $1^{\circ}$ período. A partir dos resultados obtidos, foi possível observar a necessidade de haver uma atenção psicológica aos acadêmicos de enfermagem de todos os períodos, objetivando oferecer suporte para lidarem com situações de sofrimento psíquico.

Palavras-chave: Depressão, Acadêmicos do Curso de Enfermagem, Inventário de Depressão de Beck II.

\section{INTRODUÇÃO}

Depressão "uma doença da atualidade" este termo tem sido muito utilizado nos meios científicos e divulgado nas mídias. Inicialmente, os sintomas de tristeza, ansiedade e tendência ao suicídio eram 
denominados de melancolia. Termo criado há mais de 25 séculos, designava sintomas ou caracterizava estados mentais. A partir do século XVII, ocorreram várias transformações, entre elas a substituição do termo melancolia por depressão e a psiquiatria surge como uma especialidade médica. Ao longo do século XX, diversos termos foram estudados e debatidos, como a questão, por exemplo, da natureza endógena ou exógena da depressão e os termos unipolar e bipolar. Talvez a mais marcante das mudanças tenha sido a de considerar a depressão como doença ou transtorno afetivo ou de humor (MAXWUELL, 2010).

De uma forma geral, essa doença consiste em um transtorno mental universal, cuja principal perturbação é a alteração do humor ou do afeto. A alteração do humor reflete negativamente em todas as atividades da pessoa afetada. Queda de produtividade, perda de interesse e falta de iniciativa tanto no trabalho como no estudo, são sintomas que causam sérios prejuízos sociais ao doente. Diante dessas síndromes, a Depressão é considerada um problema de saúde púbica. No século XXI a depressão tem sido responsável pela mais alta carga de doença entre as que têm como característica o transtorno mental. A sobrecarga não é somente para o indivíduo que sofre, mas também para seus familiares e cuidadores (MOREIRA; FUREGATO, 2013).

A Organização Mundial de Saúde (OMS) estima que haja no mundo 350 milhões de pessoas que vivem com depressão e deverá afetar mais pessoas do que qualquer outro problema de saúde nos próximos anos, incluindo câncer e doenças cardíacas. A depressão geralmente tem um custo alto, não só em termos financeiros, mas também podem custar relacionamentos, empregos e, até mesmo a própria vida (ABELHA, 2014).

No Brasil dados do Instituto Brasileiro de Geografia e Estatística (IBGE) mostram que a depressão é a quarta doença crônica mais diagnosticada, seguida da hipertensão e câncer. Cerca de $42 \%$ são atendidos em consultórios particulares e 33,2\% recorrem à unidade básica de saúde, gerando altos custos econômicos e sociais para o Governo (IBGE, 2013).

Uma população que merece atenção, por estar em contato com o sofrimento psíquico, é o de estudantes e profissionais da área da saúde. Esta parcela da sociedade é marcada constantemente por incertezas e ansiedades, que devem ser cuidadosamente consideradas, uma vez que ao serem vivenciadas, revelam os próprios sentimentos, como também a dificuldade em manejá-los. Essas situações provocam uma reação de choque entre o "bom" e o "ruim", gerada principalmente pela angústia decorrente da inadaptação do indivíduo frente a uma nova situação (OLHER, 2012).

Dados da OMS revelam que a depressão é um caso de saúde pública em todas as regiões do mundo. Estudos mostram que metade dos estudantes universitários brasileiros vivenciou algum tipo de crise emocional no ano de 2011, onde a depressão foi a mais representativa: atingindo cerca de $15 \%$ dos discentes (SIMAS, 2012).

Diante deste quadro é que apresentamos este trabalho que tem como objetivo ressaltar a importância de se identificar a prevalência (número de casos em uma determinada população) de sintomas depressivos entre os acadêmicos da Faculdade Metropolitana da Amazônia (FAMAZ), bem como, alertar para a necessidade de elaboração de ações que visem oferecer maior cuidado e orientação para que o aluno possa lidar com o problema psíquico. 


\section{MATERIAL E MÉTODOS}

O presente estudo trata-se de uma pesquisa de abordagem quantitativa de caráter exploratório.

O instrumento aplicado foi o Inventário de Depressão de Beck II - BDI-II. Refere-se à tristeza, pessimismo, fracasso passado, perda de prazer, sentimento de culpa, sentimento de punição, auto-estima, autocrítica, pensamentos ou desejos suicidas, choro, agitação, perda de interesse, indecisão, desvalorização, falta de energia, alterações no padrão do sono, irritabilidade, alterações do apetite, dificuldades de concentração, cansaço ou fadiga e perda de interesse por sexo (FINGER, 2008).

O BDI consiste em um questionário de auto relato com 21 premissas, referentes ao atual momento do sujeito e quantificadas em uma escala de 4 pontos de intensidade ( 0 a 3). O propósito desta escala é avaliar a sintomatologia da depressão. É um instrumento de fácil manipulação e aplicação, além de possuir grande aceitação. Os escores variam de zero até 63 , onde o zero indica não existir nenhum traço de sintomas depressivos, enquanto o escore mais alto indica maior gravidade dos sintomas. $\mathrm{O}$ guia de interpretação é o que se segue: (a) $0=$ sem depressão; (b) 10 á 16 = indica estado de depressão leve; (c) 17 á 29 = compreende um estado de depressão moderada; e (d) 30 á 63 = indica um estado de depressão severa. O BDI pode ser aplicado em indivíduos com idade igual/superior á 13 anos (FINGER; ARGIMON, 2013).

A pesquisa foi realizada na Faculdade Metropolitana da Amazônia (FAMAZ), que é uma instituição de ensino superior privado integrada ao Grupo Educacional Euro-Americano com sede em Belém do Pará, realizada com acadêmicos do curso de enfermagem do $1^{\circ}, 4^{\circ}$ e $8^{\circ}$ períodos.

Inicialmente foi feito um pré-contato com a coordenação responsável pelo curso de enfermagem para autorizar a coleta de dados de nossa pesquisa.

A pesquisa foi submetida à aprovação do comitê de ética da pesquisa (CEP), do consentimento institucional e assinatura do termo de consentimento livre e esclarecido pelos acadêmicos, os quais foram esclarecidos sobre os objetivos do estudo e aceitabilidade em participar da pesquisa, orientamos no preenchimento do instrumento. A coleta dos dados foi realizada em salas de aula, em horário previamente agendado com os alunos e professores e com o consentimento da coordenação do curso.

\section{RESULTADOS}

A pesquisa foi realizada no mês de setembro de 2015, com alunos do primeiro, quarto e oitavo períodos, dos turnos vespertino e noturno do Curso de Enfermagem da Faculdade Metropolitana da Amazônia (FAMAZ). O número de total de acadêmicos matriculados no curso e que estão cursando regularmente os períodos mencionados acima é de 217, destes 147 participaram, 57 não estavam na faculdade, 13 se recusaram a participar da aplicação do Inventário de depressão de Beck - IDB.

Mais de 53\% dos participantes apresentaram sintomas de depressão, sendo que destes 28,57\% apresentaram sintomas de depressão leve, 21,08\% apresentaram sintomas de depressão moderada, e $3,40 \%$ apresentam depressão severa. (Tabela 1).

Tabela 1. Classificação dos sintomas entre os participantes da pesquisa (2015) 


\begin{tabular}{|c|c|c|c|}
\hline IDB & $\begin{array}{c}\text { Frequência } \\
\text { Absoluta }\end{array}$ & $\begin{array}{c}\text { Frequência } \\
\text { Percentual }\end{array}$ & $\begin{array}{c}\text { Frequência } \\
\text { Acumulada }\end{array}$ \\
\hline Sem Sintomas Depressivos & 69 & $46,94 \%$ & $100 \%$ \\
\hline Sintomas Leves & 42 & $28,57 \%$ & $53,05 \%$ \\
\hline Sintomas Moderado & 31 & $21,08 \%$ & $24,48 \%$ \\
\hline Sintomas Severos & 5 & $3,40 \%$ & $3,40 \%$ \\
\hline TOTAL & 147 & $100 \%$ & - \\
\hline
\end{tabular}

\section{CARACTERÍSTICAS DOS PARTICIPANTES}

A maioria dos participantes (56,46\%) era de adultos jovens, com idade até 29 anos (ECA, 2013). Em relação ao gênero dos participantes, a maior tendência foi do sexo feminino (F) com 85,03\%, o que corresponde a mais de cinco mulheres para cada homem (M) do curso, considerando a razão (F/M) de 5,68. A variação da idade dos homens está entre 18 a 48 anos, com média de 27,81 anos e desvio padrão de 9,07 , enquanto que a do sexo feminino é de 17 a 53 anos, com média de 28,18 anos e desvio padrão de 8,29 .

A maioria dos participantes da pesquisa não exerce atividade como técnico de enfermagem (58,5\%). A distribuição dos participantes por semestre foi equilibrada, considerando os turnos vespertino e noturno, com 30,61\% dos participantes do primeiro período, 38,77\% de acadêmicos do quarto período e 32,65\% de alunos do oitavo período (Tabela 2).

Tabela 2. Análise descritiva dos dados característicos.

SEXO 